\title{
Yaşı hastalarda servikal özofagustan yabancı cisim çıkarılması: 2 olgu sunumu
}

\author{
Foreign body in cervical esophagus in elderly patients: 2 case reports
}

\author{
Ahmet UYANIKOĞLU1 ${ }^{2}$, Umut SERT², Hüseyin SERT ${ }^{3}$, Çiğdem CINDOĞLU² \\ Harran Üniversitesi Tip Fakültesi, ${ }^{1}$ Gastroenteroloji, ${ }^{2}{ }_{c ̧}$ Hastalıkları Bilim Dall, ${ }^{3}$ Anesteziyoloji ve Reanimasyon Bilim Dall, Şanluurfa
}

\begin{abstract}
Özofagusa yabancı cisim takılması ve çıkarılması çocukluk çağında sık görülürken erişkinlerde daha az görülür. Ancak dişi olmayan yaşlllarda çiğnenmeden yutulan yiyecekler ozzofagusa takılabilmektedir. Burada özofagusta yabancı cisim olan iki yaşlı hasta sunulmuştur. 1. olgu yutma güçlüğü ve boğaza takılma şikayeti ile müracaat eden ve proksimal özofagustan kurutulmus et çıkarılan 84 yașında kadın hasta idi. 2. olgu benzer șikayetlerle müracaat eden ve proksimal özofagustan tavuk eti çıkarılan 85 yaşında kadin hasta idi. lleri yașta çiğneme problemleri olan hastalarda yutma güçlügüu olduğunda yabancı cisim akla gelmelidir. Proksimal özofagus en sık yabancı cisim takılan kısımdır, dikkatli değerlendirilerek endoskopik olarak çıkarılabilir.
\end{abstract}

Anahtar kelimeler: Gastroskopi, özofagus, yabancı cisim, yaşlı hasta
Insertion and removal of esophageal foreign bodies is seen in childhood, but less frequently in adults. However, in the elderly, swallowing without chewing can cause food to lodge in the esophagus. In this case report, two elderly patients with foreign bodies trapped in the esophagus are presented. First, an 84 year old female patient with complaints of swallowing difficulties and a sore throat presented with dried meat trapped in the proximal esophagus; the food was removed. Second, an 85 year old female patient with similar complaints was admitted and chicken meat was removed from the proximal esophagus. Foreign bodies should be considered in elderly patients who present with chewing problems and difficulty swallowing. The proximal esophagus is the most common site for foreign bodies to be lodged and should be carefully evaluated and removed by endoscopy.

Key words: Gastroscopy, esophagus, foreign body, elderly patient

\section{GİRIS}

Özofagus yabancı cisimleri, ciddi morbidite ve mortaliteye yol açabilir. Amerika Birleşik Devletleri'nde her yll yaklaşık 1.500 kişinin özofagial yabancı cisme bağlı öldüğü tahmin edilmektedir (1). Yutulan yabancı cisimler yaş gruplarına ve yöresel özelliklere göre değişkenlik göstermektedir (2). Ileri yaşlarda görülen yabancı cisimlerde morbidite ve mortalite riski daha fazladır $(3,4)$.

Tüm gastrointestinal yabancı cisimlerin \%28-68'ini özofagus yabancı cisimleri oluşturur. Özofagus yabancı cisimlerinin çoğu krikofaringeus kası seviyesinde yerleşir. Birçok yabancı cisim gastrointestinal sisteme zarar vermeksizin spontan olarak barsak yoluyla çıkar. Bununla birlikte özofagusu geçen olgularm \%10-20'sinde nonoperatif müdahale ve sadece \%1 veya daha azında cerrahi müdahale gerekir (5).

Özofagus apendiks hariç mide barsak kanalının en dar yeridir ve anatomik darlıklarından dolayı yabancı cisimlerin sıklıkla takılabildiği bir organdır (6). Tanıya götüren nokta yabancı cisim yutma hikayesidir. Hikayenin kesin olmaması tanının gecikmesine neden olmaktadır (7). Tanıda geç kalındığında tedavisi zorlaşmakta olup, komplikasyonları ciddi ve hayatı tehdit edicidir. Bu nedenle yabancı cisimlerin erken tanı ve tedavisi çok önemlidir $(8,9)$. Bilgisayarlı tomografi (BT)

yabancı cismin yerini erken dönemde tam olarak saptamada ve endoskopiyle erkenden yabancı cismin çıkarılarak komplikasyon riskinin azaltılmasında faydalıdır (10).

Yabancı cismin özofagusta 24 saatten fazla kalmasına izin verilmemelidir. Acil tedavi endikasyonu vardır $(11,12)$. Özofagus yabancı cisimleri endoskopik yöntemlerle güvenli bir biçimde çıkarılmaktadır (6). Yabancı cisim yutulmasında mortalite oranı \% l'in altındadır (13).

Bu yazıda yutma güçlüğü ve boğazda takılma şikayeti ile kliniğimize müracaat eden ve proksimal özofagustan başarılı bir şekilde kurutulmuş et ve tavuk eti çıkarılan 2 olgu sunulmuştur.

\section{OLGU 1}

Yaklaşı 12 saat önce yemek yeme sonrası yutma güçlüğü ve boğaza takılma şikayeti başlayan 84 yaşında kadın hasta, özofagusta yabancı cisim şüphesi ile Mardin'den kliniğimize sevkedildi. Hastanın değerlendirilmesinde dişlerinin olmadığı ve şikayetinin kurutulmuş et yedikten sonra başladığı öğrenildi. Hasta ön değerlendirmeden sonra endoskopi ünitesine alındı. 


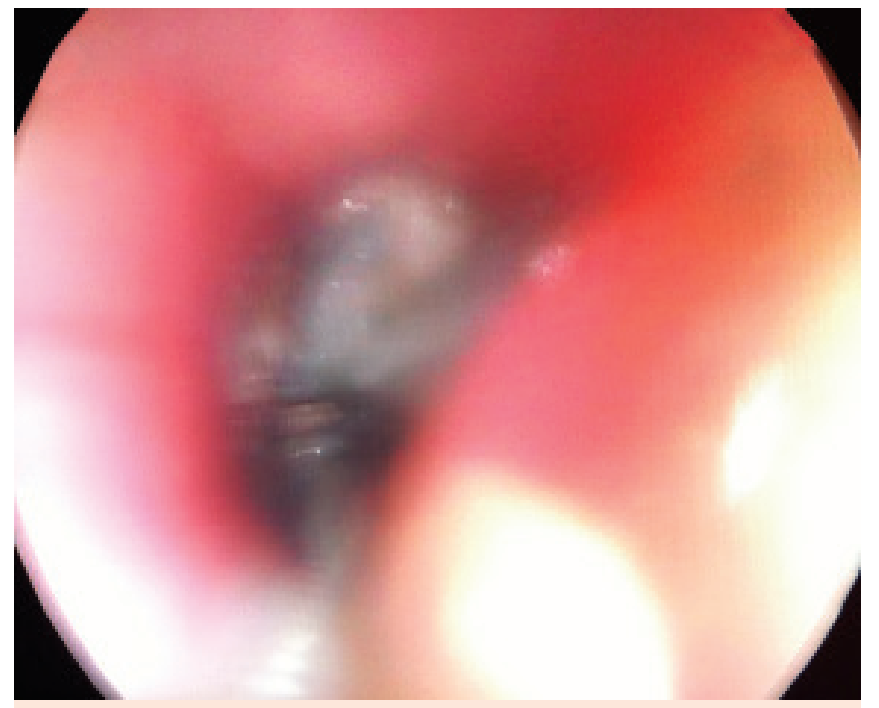

Resim 1. Birinci olguda proksimal özofagusta yabancı cismin gastroskopik görünümü.

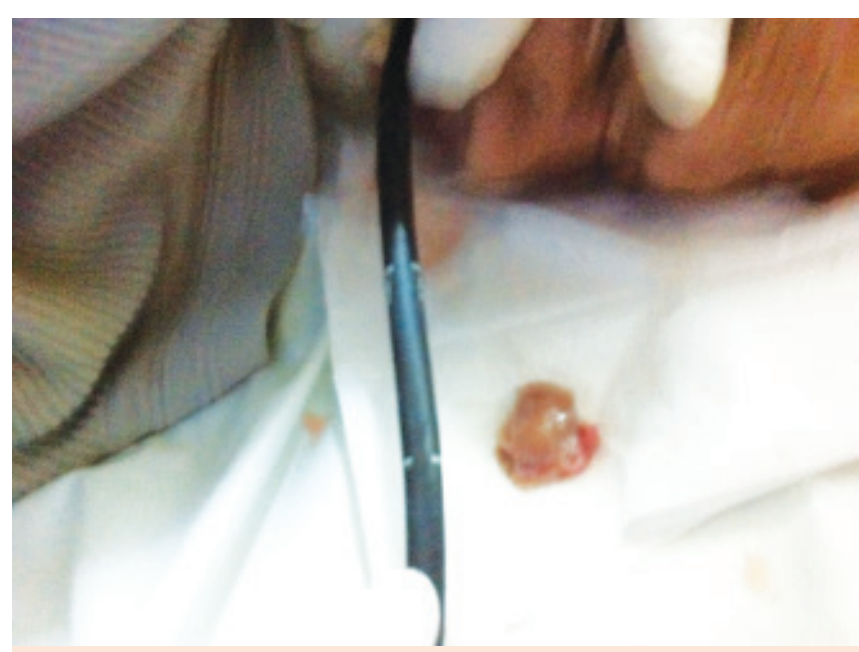

Resim 2. Birinci olguda özofagustan yabancı cisim çıkarılması (kurutulmuş et).

Ksilokain ile lokal anestezi sonrası gastroskopla girildi. Ön kesici dişlerden itibaren 15. cm'de endoskopun geçişine izin vermeyen darlık saptandi. Hasta huzursuz olduğundan anestezist eşliğinde $0,5 \mathrm{mg} / \mathrm{kg}$ dozunda intravenöz bolus, sonrası idamede $4 \mathrm{mg} / \mathrm{kg} / \mathrm{saat}$ dozunda anestezist eşliğinde propofol ile sedatize edildi. Proksimal özofagusta sedef renkli bir parlaklık görüldü (Resim 1), bunun yutulan şey olabileceği düşünüldü. Yabancı cisim dişli forsepsi ile tutuldu ve geriye doğru endoskopla beraber çıkarıldı. Yabancı cismin yaklaşı 2*3 cm'lik kurutulmuş et olduğu görüldü (Resim 2). 3 gün serviste takip edilen, komplikasyon gelişmeyen hasta şifa ile taburcu edildi.

\section{OLGU 2}

Yaklaşık 24 saat önceki yemek sonrası yutma güçlügü ve boğazına takılma şikayeti ile sevkedilen 85 yaşındaki kadın has- ta endoskopi ünitesine alındı. Hastanın değerlendirilmesinde dişlerinin olmadığı ve tavuk eti yedikten sonra şikayetlerinin başladığı ögrenildi, hastanın tavuk kemiği yutmuş olabileceği düşünüldü. 24 saat geçtiğinden yabancı cismin lokalizasyonunu ve yutulan cismin ne olduğunu değerlendirebilmek için toraks BT'si çekildi. BT'de özofagus lümeni özellikle tiroid glandı seviyesinde ileri derecede oblitere görünümde idi, stenoz görünümü arkus aorta düzeyinde devam etmekteydi, lümendeki yapının yumuşak doku yapısında olduğu ve kemik dansitesinde görünüm olmadığı dikkat çekti (Resim 3). Anestezist eşiliğinde sedasyon amaçlı $0,5 \mathrm{mg} / \mathrm{kg}$ dozunda propofol intravenöz bolus sonrası idamede $4 \mathrm{mg} / \mathrm{kg} / \mathrm{saat}$ dozunda propofol infüzyonuyla gastroskopla girildi. Ön kesicilerden itibaren 16-17. cm'de servikal özofagusta lümeni tıkayan, beyaz renkli yabancı cisim görüldü, bunun yutulan yabancı cisim olabileceği düşünüldü (Resim 4). Yabancı cisim forsepsi ve tripotla parça parça çıkarıldı (Resim 5). Kalan kısım endoskopla ilerletilerek mideye gönderildi. Kontrol gastroskopisinde servikal özofagusta erozyon görüldü. 2 gün serviste takip edilen, komplikasyon gelişmeyen hasta şifa ile taburcu edildi.

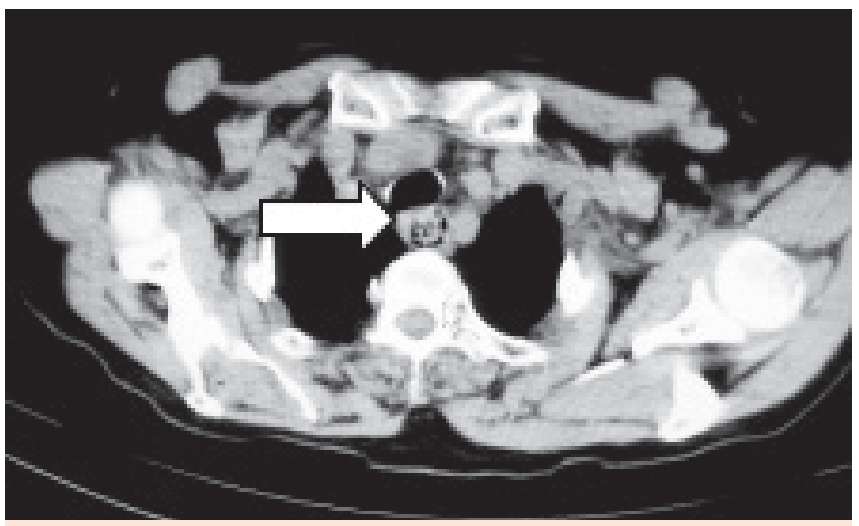

Resim 3. Ikinci olguda bilgisayarlı tomografide özofagus lümeninde yabancı cismin yumuşak doku dansitesinde kitle şeklinde görüntüsü (okla işaretli).

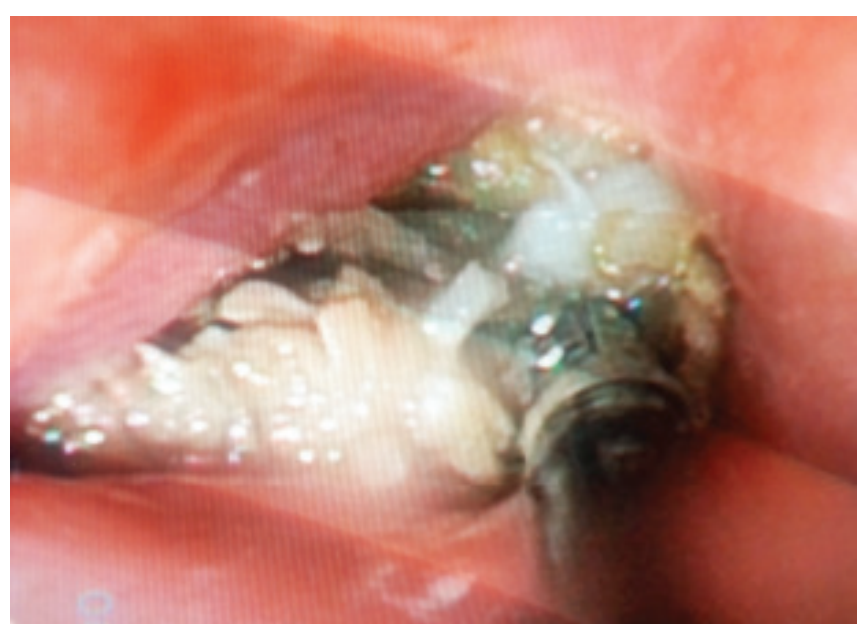

Resim 4. Ikinci olguda proksimal özofagusta yabancı cismin gastroskopik görünümü. 
Resim 5. Ikinci olguda özofagustan çıkarılan yabancı cisim (tavuk eti).

\section{TARTIȘMA}

Özofagus yabancı cisimleri çocuklarda daha sık olmak üzere her yaş grubunda görülebilmektedir. Her yaşta görülebilmekle birlikte özofagusta görülen yabancı cisimlerin \%80'inin 15 yaş altında görüldügü bildirilmiştir $(9,14,15)$. Bizim hastalarımızın her ikisi de ileri yaş hastalar olması ilginçti.

Özofagus yabancı cisimlerine bağlı en fazla rastlanan semptomlar boyun ağrısı, disfaji, takılma ve batma hissi, hipersalivasyon ve özofageal obstrüksiyona bağl gelişen trakeal aspirasyondur (16). Her iki hastamızda da ortak semptom boğaza takılma hissiydi.

Özofagusta yabancı cisim tanısına götüren en önemli nokta hikayedir (6). Türkyılmaz ve arkadaşlarını yabancı cisim yutma şüphesi ile izlenen 188 hastayı incelediği seride hastaların 158'inde (\%84) yutma hikayesi, 145’inde (\%77.1) gögüs grafisinde pozitif bulgu saptanmıştır. Yabancı cisimlerin 137 tanesi (\%79.2) hipofarenks ve servikal özofagusta saptanmıştır. En sik saptanan cisimler 72 hastada madeni para, 42 hastada kemik iken 15 hastada (\%8) bir şey saptanmamıştır. 5 hastada cerrahi müdahale ile yabancı cisim çıkarılmış. 2 hastada özofageal rüptür (\% 1.06), 1 hastada mortalite (\%0.53) görülmüştür. Komplikasyonların erken tanı ve müdahale ile önlenebileceği ve rijit endoskopinin güvenli olduğu bildirilmiştir (17). Hastalarımızın her ikisinin hikayesinde şikayetlerin yemek sonrası başlaması, ağız muayenesinde hastaların dişlerinin olmaması, yabancı cismin hipofarenkste olmaması, yenilen şeylerin özofagusa takılmış olabileceğini düşündürmüştür.

Yutulan yabancı cisimler yaş gruplarına ve yöresel özelliklere göre değişkenlik göstermektedir. Ileri yaşlarda görülen yabancı cisimlerde morbidite ve mortalite riski daha fazladır (2-4). Ilk hastamız Mardin'den gelmişti, kurutulmuş etin o yöreye has bir yiyecek olduğu öğrenildi (Resim 2). Hastalar1mız yaşlı olmasına rağmen morbidite ve mortalite gelişmedi, her ikisi de şifa ile taburcu edildi.

Yabancı cisim tanısında geç kalındığında tedavisi zorlaşmaktadır. Bu nedenle yabancı cisimlerin erken tanı ve tedavisin- de ilk 24 saat kritiktir ve acil tedavi endikasyonu vardır (8, 12,18). Fleksibl endoskoplar kullanılmadan önce Brooks ve arkadaşlarının, özofagustan 26 et parçasını rijit özofagoskopla çıkardığı çalışmasında, 3 (\%11,5) olguda perforasyon ve l'inde (\%3,8) mortalite bildirmiştir (19). Her iki olgumuzda da herhangi bir komplikasyon gelişmeden fleksibl gastroskop ile yabancı cisimler çıkarılmıştır.

Erbil B. ve arkadaşlarının yaptığı çalışmada yabancı cisim en sık özofagusta, en sık yutulan şey yiyecek (\%52) olarak saptanmıştır. Düz grafiler yutulan radyoopak cisimlerin lokalizasyonunun saptanmasında faydalı iken, fiberoptik metodların yutulan cisim radyoopak olmasa bile tanı ve tedavide kullanışlı olduğu bildirilmiştir (20). Bizim hastalarımızda da yutulan materyaller özofagusa takılmıs ve bunların yiyecek olduğu (kurutulmuş et ve tavuk eti) saptanmış, fiberoptik endoskoplarla tesbit edilerek çıkartılmışlardır.

Yutulan keskin cisimlerde oro ve hipofarenks muayene edilmesi gerektiği, negatifse hastada tanı ve tedavinin doğru yapılması için ilk seçilecek tetkikin multidedektörlü BT olması gerektiği bildirilmiştir. Yabancı cisimlerin yutulmasında tanıda BT’nin \%100 sensitif \%92.6 spesifik, negatif prediktif değeri \%100 ve pozitif prediktif değeri \%97.9 olarak bildirilmiştir. Özofagusta yabancı cisim yutulmasında erişkinlerde komplikasyon riski yüksektir. BT yabancı cismin yerini erken dönemde tam olarak saptamada ve endoskopiyle erkenden yabancı cismin çıkarılarak komplikasyon riskinin azaltılmasinda faydalıdır. Bu nedenle BT'nin özofageal yabancı cisimlerin erken tanısında ilk seçilecek görüntüleme yöntemi olduğu bildirilmiştir Özofagusta yabancı cisim 24 saatten fazla kaldığında çıkarılması zor olmaktadır. 24 saati geçen müdahalede işlemin odinofaji ile beraber daha fazla özofageal ülserasyona yol açtı̆̆ bildirilmiştir. Multidedktörlü BT faringoözofageal yabancı cisim tanısında radyografiden üstün olup, komplike olgularda, özellikle keskin veya delici maddelerin yutulmasinda daha fazla bilgi vermektedir (21-23). Bizim hastalarımızın ilkinde BT çekilmedi, ikincisinde 24 saat geçtiği için önce multidedektörlü BT çekildi. Servikal özofagus seviyesinde özofagus lümeninde yumuşak doku dansitesinde kitle görüldü, kemik düşündürecek opasite görülmedi (Resim 3). Bu olguda BT yabancı cismin lokalizasyonu, natürü hakkında faydalı bilgiler sağlamıs olup, yutulan tavuk etinin çıkarılamayan kısmı, kemik olmadığı ve perforasyona neden olmayacağ düşünülerek mideye doğru ilerletilerek pasaj sağlanmıştır.

Özofageal yabancı cismin çıkarılmasında genel anestezi alıında özofagoskopinin ilk seçenek olduğu, perforasyon ve diğer acil durumlarda boyun yan duvarı veya torakotomi ile zamanında erken cerrahi müdahalenin hayati önemde olduğu bildirilmiştir (24). Her iki olguda anestezist eşliğinde güvenli bir şekilde propofol ile anestezi sağlanmış ve fleksibl gastroskopla yabancı cisimler çıkarılmış, cerrahi müdahaleye gerek kalmamıştır. 
Sonuç olarak özofagusa yabancı cisimler sıklıkla proksimal özofagusa takılır, hastadan alınacak anamnez ve ilk değerlendirme önemlidir. Dişleri olmayan yaşlı hastalarda çiğnenmeden yutulan katı yiyeceklerin de proksimal özofagusa takı-

\section{KAYNAKLAR}

1. Vizcarrondo FJ, Brady PG, Nord HJ. Foreign bodies of the upper gastrointestinal tract. Gastrointest Endosc 1983;29:208-10.

2. Cheng W,Tam PK. Foreign-body ingestion in children:experience with 1.265 cases. J Pediatr Surg 1999;34:1472-6.

3. Temple DM, McNeese MC. Hazards of battery ingestion. Pediatrics 1983;71:100-3.

4. Nandi P, Ong GB. Foreign body in the oesophagus: review of 2394 cases. Br J Surg 1978;65:5-9.

5. Athanassiadi K, Gerazounis M, Metaxas E, Kalantzi N. Management of esophageal foreign bodies: a retrospective review of 400 cases. Eur J Cardiothorac Surg 2002;21:653-6.

6. Çobanoğlu U, Yalçınkaya 1. Özofagus yabancı cisimleri: 175 olgunun analizi [Esophageal foreign bodies: analysis of 175 patients]. Turkish J Thorac Cardiovasc Surg 2008;16:244-9.

7. Chiu YH, Hou SK, Chen SC, et al. Diagnosis and endoscopic management of upper gastrointestinal foreign bodies. Am J Med Sci 2012;343:192-5.

8. Çobanoğlu U, Can M. 0-7 yaş dönemi çocuklarda özofagus yabancı cisimleri. Van Tip Dergisi 2008;15:51-7.

9. Inci I, Özçelik C, Ülkü R, Eren N. Özofagus yabancı cisimleri: 682 olgunun incelenmesi. GKDC Dergisi 1999;7:148-52.

10. Liu YC, Zhou SH, Ling L. Value of helical computed tomography in the early diagnosis of esophageal foreign bodies in adults. Am J Emerg Med 2013;31:1328-32.

11. Wu WT, Chiu CT, Kuo CJ, et al. Endoscopic management of suspected esophageal foreign body in adults. Dis Esophagus 2011;24:131-7.

12. Frossard JL, de Peyer R. An unusual digestive foreign body. Case Rep Gastroenterol 2011;5:201-5.

13. Tiryaki T, Doğancı T, Livanelioğlu Z, Atayurt FH. Çocukluk çağında yabancı cisim yutulması. Türkiye Klinikleri J Pediatr 2004;13: 67-70. labileceği unutulmamalıdır. Özofagusta yabancı cisimlerde müdahale öncesi BT ile değerlendirme yol göstericidir. Yabancı cisimler gastroskopla ilk 24 saatte, anestezi altında güvenli bir şekilde çıkarılabilir.

14. Yavuzer S, Aslan R, Akay H, et al. Özofagus yabancı cisimleri (52 vakanın incelenmesi). AÜTF Mec 1977;30:77-106.

15. Gmeiner D, von Rahden BH, Meco C, et al. Flexibl versus rigid endoscopy for treatment of foreign body impaction in the esophagus. Surg Endosc 2007;21:2026-9.

16. O'Sullivan ST, McGreal GT, Reardon CM, et al. Selective endoscopy in management of ingested foreign bodies of the upper gastrointestinal tract: is it safe? Int J Clin Pract 1997;51:289-92.

17. Türkyılmaz A, Aydın Y, Yılmaz Ö, et al. Esophageal foreign bodies: analysis of 188 cases. Ulus Travma Acil Cerrahi Derg 2009;15:222-7.

18. Uyanıkoğlu A, Cosskun M, Albayrak F. Foreign body (chicken bone) of the cervical esophagus: endoscopic removel, Case report and review of the literature. The Turkish Journal of Academic Gastroenterology 2011;10:128-30.

19. Brooks JW. Foreign bodies in the air and food passages. Ann Surg 1972; 75:720-32.

20. Erbil B, Karaca MA, Aslaner MA, et al. Emergency admissions due to swallowed foreign bodies in adults. World J Gastroenterol 2013;19:6447-52.

21. Ma J, Kang DK, Bae JI, et al. Value of MDCT in diagnosis and management of esophageal sharp or pointed foreign bodies according to level of esophagus. AJR Am J Roentgenol 2013;201:W707-11.

22. Wu WT, Chiu CT, Kuo CJ, et al. Endoscopic management of suspected esophageal foreign body in adults. Dis Esophagus 2011;24:131-7.

23. Pinto A, Muzj C, Gagliardi N, et al. Role of imaging in the assessment of impacted foreign bodies in the hypopharynx and cervical esophagus. Semin Ultrasound CT MR 2012;33:463-70.

24. Mao Y, Nie Z, Yang F, Wu W. The clinical analysis of severe complications induced by esophageal foreign bodies. Lin Chung Er Bi Yan Hou Tou Jing Wai Ke Za Zhi 2012;26:1111-2, 1115. 